\title{
Role of shock intensity in the learned helplessness paradigm
}

\author{
ROBERT A. ROSELLINI and MARTIN E. P. SELIGMAN \\ University of Pennsylvania, Philadelphia, Pennsylvania 19104
}

\begin{abstract}
Although there have been many studies of the interference effect produced by exposure to inescapable shock, little is known about the role of shock intensity. This experiment factorially manipulated four levels of shock intensity during exposure to inescapable shock and three levels of intensity during the test for interference. Interference occurred at each training shock intensity when training and test shocks were similar. Interference was not obtained when training intensity was high but testing intensity low or medium or when training intensity was low or medium and test intensity was high. These findings pose problems for learned helplessness, learned inactivity, competing motor response, and catecholamine depletion hypotheses of the interference effect in the rat.
\end{abstract}

Dogs or rats exposed to inescapable shock subsequently often fail to learn a response to escape shock in a novel situation (Maier, Albin, \& Testa, 1973; Overmier \& Seligman, 1967). This deficit results from the uncontrollability of the shock, since animals exposed to an equal amount of shock which they can escape and nonshocked animals learn the new response (Seligman \& Beagley, 1975; Seligman, Rosellini, \& Kozak, 1975). A large amount of experimentation has focused on this phenomenon (c.f. Maier, Seligman, \& Solomon, 1969; Seligman, 1975; Seligman, Maier, \& Solomon, 1971). However, during the test for intereference, most of this research has employed either the same or a lower shock intensity than was used during exposure to inescapable shock. Typically, shock intensity was lowered from 6.0 to $4.5 \mathrm{~mA}$ from training to testing in experimentation with dogs, while it was held constant at $1.0 \mathrm{~mA}$ in the rat experimentation.

Some exceptions do exist in the literature. Overmier and Seligman (1967) found that increasing shock intensity from $6.0 \mathrm{~mA}$ for inescapable shock training to $6.5 \mathrm{~mA}$ for escape/avoidance testing did not attenuate interference. However, there was a tendency for the higher intensity group to have lower escape latencies than the lower shock group. Maier, Albin, and Testa (1973) also failed to find an effect of increasing shock intensity from training $(1.0 \mathrm{~mA})$

This research was supported by Postdoctoral Fellowship MH00980-02 from the National Institute of Mental Health to the first author and by Grant MH-19604 from the National Institute of Mental Health to the second author. The authors wish to thank Steven F. Maier, David Burdette, Ronald H. Ehrman, and Steven Seaman for their helpful criticism of this manuscript. Requests for reprints should be sent to: Robert A. Rosellini, Department of Psychology, SUNY-Albany, 1400 Washington Avenue, Albany, New York 12222. to testing $(2.5 \mathrm{~mA})$ in the rat. However, the effect of this manipulation was assessed on a fixed-ratic 1 (FR 1) shuttle response to escape shock, which in this same series of experiments was shown not to be a sensitive measure of the effect of inescapable shock in the rat.

Since little evidence is available concerning the importance of shock intensity in learned helplessness, we explored this parameter both for training and testing intensities. Different groups of rats were exposed to four different intensities of inescapable shock $(0,0.4,1.0$, and $2.0 \mathrm{~mA})$. Subsequently, onethird of each of the groups were tested for interference at one of three shock intensities $(0.4,1.0$, and $2.0 \mathrm{~mA}$ ). The test consisted of the acquisition of a fixed-ratio 3 barpress response to terminate shock, which has been shown to be sensitive to the effect of prior exposure to inescapable shock (Seligman \& Beagley, 1975).

\section{METHOD}

\section{Subjects}

The subjects were 96 male Holtzman rats, approximately 100 days of age at the start of the experiment. They were housed in individual cages and had continuous access to food and water. All animals were run during the light phase of the 12 -h light/ 12-h dark cycle.

\footnotetext{
Apparatus

Four operant chambers were used for both inescapable shock training and escape testing. Each chamber was $30.5 \mathrm{~cm}$ long, $20.3 \mathrm{~cm}$ wide, and $19 \mathrm{~cm}$ high. Two walls and the ceiling of each chamber were constructed of clear Plexiglas. The other walls were constructed of plywood. The grid floor of the chamber consisted of stainless steel rods $.64 \mathrm{~cm}$ in diameter, spaced $1.27 \mathrm{~cm}$ apart. A lever $(7.6 \times 3.8 \mathrm{~cm})$ was centered on the front wall, $7.6 \mathrm{~cm}$ above the grid floor. The lever was not present in the chamber during the inescapable shock phase of the experiment. A constant-current shock source consisting of a $600-\mathrm{V}$ ac transformer and a current-limiting resistor was used to deliver the
} 
appropriate level of shock to the animals. A subcutaneous pin electrode was mounted on the upper part of each rat's back, and their backs were shaved. Shock was delivered through the pin electrode and the grid floor of the chamber. The chambers were housed in sound-attenuating containers, equipped with a houselight and masking white noise. All programming and recording equipment was housed in a separate room.

\section{Procedure}

The experiment consisted of a 4 by 3 factorial design with four different levels of training-shock intensity and three different test intensities. The animals were randomly assigned to one of four main training groups.

On Day 1, animals were exposed to one of four levels of inescapable shock-no shock $(0 \mathrm{~mA})$, low shock $(0.4 \mathrm{~mA})$, medium shock $(1.0 \mathrm{~mA})$, or high shock $(2.0 \mathrm{~mA})$. The training session consisted of 80 trials of $15 \mathrm{sec}$ of inescapable shock of the appropriate intensity. Trials were programmed on a variable-time 60-sec schedule (range 10-110 sec). On Day 2, all animals were tested on the acquisition of a leverpress response to escape shock. The above four training groups were subdivided into three groups, each of which was tested at a different shock intensity-low shock (0.4 mA), medium shock (1.0 mA), and high shock (2.0 mA). The test consisted of 20 trials of up to $60 \mathrm{sec}$ of unsignaled shock of the appropriate intensity. Shock could be terminated by depressing the lever three times (FR 3). Trials were programmed on a variable-time 60 -sec schedule (range $10-110 \mathrm{sec}$ ). The escape latencies were recorded on each trial.

\section{RESULTS}

Overall, interference occurred when training intensity and test intensity were similar, but not when intensities were highly discrepant. Figure 1 shows the mean escape latencies on the 20 test trials as a function of shock intensity experienced during the test and training phases. A Training Intensity (4) by Test Intensity (3) by Blocks of Five Trials (4) analysis of variance showed the Training Intensity factor to be significant $[F(3,84)=3.43, p<.05]$. NewmanKeuls post hoc tests ${ }^{1}$ revealed the no-shock group to have faster escape latencies than the low-, medium-, or high-shock training groups (all ps $<.05$ ), while the three latter groups did not differ from each other. Thus, an interference effect was produced at all training intensity levels, relative to the nonpreshocked groups.

The Test Intensity factor was also significant $[F(2,84)=24.16, p<.01]$. Post hoc tests showed the low-shock group to have slower escape latencies than both the medium- $(p<.01)$ or the high-shock group $(p<.01)$. And the medium-shock group showed slower escape latencies than the high-shock group $(p<.05)$. Further post hoc tests were performed for the no-shock groups tested at different intensities. The no-shock-low-intensity group was reliably slower to escape than the no-shock-highintensity group $(\mathrm{p}<.05)$ and marginally slower than the no-shock-medium group $(.05<\mathrm{p}<.10)$. This latter group was marginally slower than the no-shockhigh-intensity group $(.05<\mathrm{p}<.10)$. So, the more intense test shock resulted in faster escape latencies.

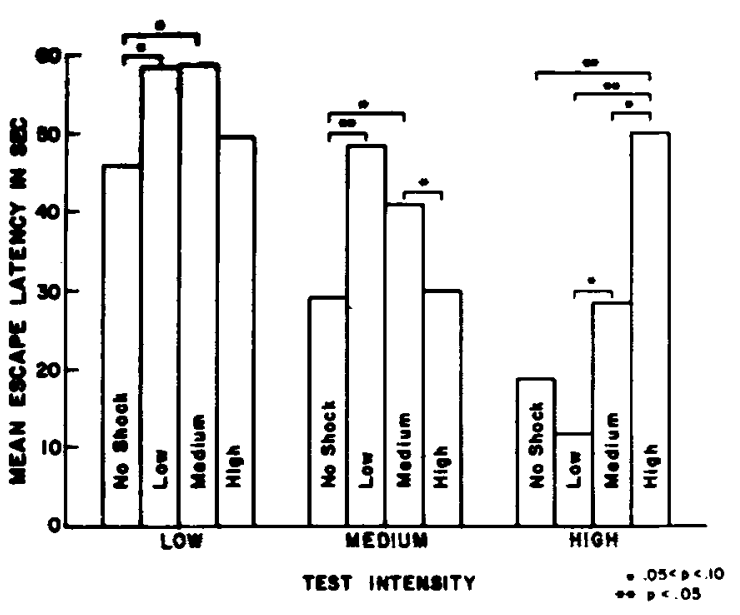

Figure 1. Mean escape latency as a function of the training and test shock intensity (no-shock $=0$, low $=0.4$, medium $=1.0$, and high $=2.0 \mathrm{~mA}$ ) for the 20 test trials.

In addition, the Training by Test Intensity interaction was significant $[F(6,84)=5.49, p<.01]$. This interaction appears to result from the low and medium training intensities producing interference at low and medium testing intensities but not at high testing intensity, whereas the high training shock produced interference at high but not at medium or low intensities. If we assume that medium and low shock are subjectively similar to each other and different from high shock, we may conclude that intereference only results when training and test shock are similar. This interaction is shown in Figure 1 with the significance levels of post hoc comparisons at each test intensity level.

The groups experiencing increased shock intensity from either low to high or medium to high showed escape latencies approximately equal to those of the no-shock-high controls (all ps $>.10$ ). However, the low-medium shift group had slower latencies than either the no-shock-medium or the high-medium (ps $<.05$ ) groups. The groups exposed to decreasing shock intensity from high to either medium or low showed escape latencies equivalent to the no-shock controls tested at these intensities ( $\mathrm{ps}>.10$ ). The medium-low group, however, showed latencies marginally longer than the no-shock-low control group $(.05<\mathrm{p}<.10)$ but did not differ from the low-low group $(p>.10)$. This pattern is consistent with the assumption that low and medium are similar and different from high intensity.

The groups that did not experience a change in shock intensity from training to testing did not differ significantly from each other (all ps $>.10$ ). Neither the Block of Trials factor nor any of the interactions containing that factor were found to be significant (all Fs $<2.0$ ). 


\section{DISCUSSION}

These findings show that the interference effect can be produced by inescapable shock of high, medium, as well as low intensity. Animals showed a deficit escaping either a $1.0-$ or $2.0-\mathrm{mA}$ shock when they were previously exposed to that level of inescapable shock, relative to animals given no pretraining shock but tested at these shock levels. Animals trained at $0.4 \mathrm{~mA}$ and tested at $0.4 \mathrm{~mA}$ showed a marginal escape deficit relative to nonpreshocked animals tested at this intensity. The low test intensity $(0.4 \mathrm{~mA})$ does not seem sufficiently aversive to support reliable escape behavior in naive rats, and thus may not be wholly adequate for comparisons with preshocked groups.

The magnitude of the difference in escape latencies between the no-shock and the preshocked animals experiencing no change in intensity from training to testing tended to be directly related to the test shock intensity. This relationship seems to be due mostly to the faster escape in the no-shock animals with increasing test intensity. So intensity of the testing shock is an important determinant of the magnitude of the interference effect obtained, although its major effect seems to be to produce faster escape latencies in the no-shock controls. Higher shock probably elicits more responding.

The major results of the experiment may be summarized as follows. First, interference decreased with an increase in test intensity over training intensity. This is particularly evident in the medium-high and low-high shock groups. Observation of these animals showed them to emit high levels of activity during the high shock. This may have resulted in more "shock-elicited" exposures to the response-shock termination contingency than the animals tested with lower shock intensities. This result is consistent with the finding of Overmier and Seligman (1967) in dogs, who found no reduction in interference when they increased intensity from training $(6.0 \mathrm{~mA})$ to testing (6.5 mA). Similarly, we obtained a deficit when shock intensity was increased from training $(0.4 \mathrm{~mA})$ to testing $(1.0 \mathrm{~mA})$. However, the present results also limit the generality of the effect, since no interference was obtained when intensity was increased from either 0.4 or $1.0 \mathrm{~mA}$ during training to $2.0 \mathrm{~mA}$ in testing.

The second major finding was that the high training shock produced interference only at high test intensity but not at medium or low intensity. The learned helplessness hypothesis (Maier \& Seligman, 1976) cannot readily account for the specificity of the interference effect produced by exposure to highintensity inescapable shock at the same time as accounting for its generality across reinforcers (see below). However, it is equally difficult to account for this result by competing motor response (Bracewell
\& Black, 1974), learned inactivity (Glazer \& Weiss, 1976), or catecholamine depletion hypotheses (Weiss, Glazer, \& Pohorecky, 1976). Competing motor response and learned inactivity depend on reinforcement of the interfering motor pattern by shock termination. The greater the magnitude of reinforcement (i.e., the higher the shock intensity in training), the better learned should the interfering response pattern be. These hypotheses should predict that high-intensity training will produce the greatest interference at all test intensities. This, of course, was not the case. Similar predictions are made by the catecholamine depletion view since greater depletion is alleged to occur at high training intensity.

The third major result was that interference was maximal when the training and testing intensities were similar. Low and medium training shock produced interference with low and medium test shock but not with high test shock. High training shock produced interference at high test shock but not at low or medium testing intensities. As the difference between the test and the training intensities increased, the interference effect decreased. This result poses a problem for the learned helplessness theory. The basic process in learned helplessness is learning of response-outcome independence. How general is the stimulus control of this learning alleged to be? In principle, the wideness or narrowness of the generalization gradient is an empirical question. But the evidence has suggested that the gradient is wide (see Seligman, 1975, pp. 31-37, for a discussion). Goodkin (1976) found uncontrollable food delivery to interfere with the acquisition of a response to escape shock. Rosellini (1978) reported that inescapable shock interfered with the acquisition of instrumental responding for food. Altenor, Kay, and Richter (1977) reported as much interference with the acquisition of a response to escape either shock or from an underwater maze following either uncontrollable shock or underwater experience.

The present results suggest a much narrower generalization gradient, unless one assumes that the subjective difference between medium and high shock is larger than between shock and food or shock and cold water. This finding is also difficult for the catecholamine depletion hypothesis to explain. Learned inactivity and competing motor response hypotheses are consistent with the result since they would claim post hoc that the stimulus control of the interfering pattern generalizes narrowly. Unfortunately, this claim is inconsistent with the Altenor, Kay, and Richter (1977), Goodkin (1976), and Rosellini (1978) results showing generalization across reinforcers. So these pose a problem for all theories of the interference effect in rats.

At any rate, these results show that similarity of training and testing shock is an important modulator of the interference obtained following exposure to 
inescapable shock when shock escape is the test. Similarly, Lawry, Lupo, Overmier, Kochevar, Hollis, and Anderson (1978) found the qualitative properties of inescapable shock to be an important determinant in the deficit obtained in the acquisition of escape/ avoidance responding in both dogs and rats. They found that, while exposure to pulsating or continuous alternating current or continuous direct current shock produced a deficit in the subsequent acquisition of an escape/avoidance response, pulsating direct current shock did not result in a later deficit. The present findings, taken in conjunction with the Lawry et al. (1978) study, suggest that, when shock escape is the test, quantitative as well as qualitative variables of the shock may come to act as discriminative stimuli for whatever is learned during inescapable shock-be it helplessness, competing motor response (Miller \& Weiss, 1969), inactivity (Glazer \& Weiss, 1976), or catecholamine depletion (Weiss, Glazer, \& Pohorecky, 1976).

To the extent that the learned helplessness position, or indeed any of the alternative positions, claims a wide generalization gradient for whatever is learned during exposure to uncontrollable events to account for the transsituational nature of the interference phenomenon, it is not obvious how they can account for the specificity observed in the present and in the Lawry et al. (1978) experiments. Additional research must be conducted to investigate the conditions under which interference is narrow or broad and the exact mechanisms underlying both the apparent specificity of this phenomenon within the shock test situation and its lack of specificity in cross-reinforcer situations.

\section{REFERENCES}

Altenor, A., Kay, E., \& Richter, M. The generality of learned helplessness in the rat. Learning and Motivation, 1977, 8, 54-61.

Bracewell, R. J., \& Black, A. H. The effects of restraint and noncontingent preshock on subsequent escape learning in the rat. Learning and Motivation, 1974, 5, 53-69.

Glazer, H. I., \& WEISS, J. M. Long-term interference effect: An alternative to "learned helplessness." Journal of Experimental Psychology: Animal Behavior Processes, 1976, 2, 202-213.
Goodkin, F. Rats learn the relationship between responding and environmental events: An expansion of the learned helplessness hypothesis. Learning and Motivation, 1976, 7, 382-393.

LAWRY, J. A., Lupo, V., OVERMier, J. B., KocheVar, J., Hollis, K. L., \& ANDERson, D. C. Interference with avoidance behavior as a function of qualitative properties of inescapable shock. Animal Learning \& Behavior, 1978, 6, 147-154.

Maier, S. F., Albin, R. W., \& Testa, T. J. Failure to learn to escape in rats previously exposed to inescapable shock depends on the nature of the escape response. Journal of Comparative and Physiological Psychology, 1973, 85, 581-592.

Maier, S. F., \& Seligman, M. E. P. Learned helplessness: Theory and evidence. Journal of Experimental Psychology: General, 1976, 105, 3-46.

Maier, S. F., Seligman, M. E. P., \& Solomon, R. L. Pavlovian fear conditioning and learned helplessness. In B. A. Campbell \& R. M. Church (Eds.), Punishment and aversive behavior. New York: Appleton-Century-Crofts, 1969.

Miller, N. E., \& WEISS, J. M. Effects of somatic or visceral responses to punishment. In B. A. Campbell \& R. M. Church (Eds.), Punishment and aversive behavior. New York: Appleton-Century-Crofts, 1969.

Overmier, J. B., \& Seligman, M. E. P. Effects of inescapable shock upon subsequent escape and avoidance learning. Journal of Comparative and Physiological Psychology, 1967. 63, 28-33.

RoSELLINI, R. A. Inescapable shock interferes with the acquisition of an appetitive operant. Animal Learning \& Behavior, 1978, 6. $155-159$.

Seligman, M. E. P. Helplessness. San Francisco: Freeman, 1975.

Seligman, M. E. P., \& Beagley, G. Learned helplessness in the rat. Journal of Comparative and Physiological Psychology. 1975, 88, 534-541.

Seligman, M. E. P., Maier, S. F., \& Solomon, R. L. Unpredictable and uncontrollable aversive events. In F. R. Brush (Ed.), Aversive conditioning and learning. New York: Academic Press, 1971.

Seligman, M. E. P., Rosellini, R. A., \& Kozak, M. J. Learned helplessness in the rat: Time course, immunization, and reversibility. Joumal of Comparative and Physiological Psychology, 1975, 88, 542-547.

Weiss, J. M., Glazer, H. I., \& Pohorecky, L. A. Coping behavior and neurochemical changes: An alternative explanation for the original "learned helplessness" experiments. In G. Serban \& A. Kling (Eds.), Relevance of the psychopathological animal model to the human. New York: Plenum Press, 1976.

\section{NOTE}

1. All post hoc tests are Newman-Keuls.

(Received for publication June 8, 1977; revision accepted December 14, 1977.) 